\title{
Insight
}

\section{Toward a Theory of Integrated Urban Ecology: Complementing Pickett et al.}

\author{
Robert Mugerauer $^{1}$
}

\begin{abstract}
The analyses substantially delineating "integrative studies of large urban areas as biophysical-social complexes" and the suggestions by Pickett et al. in "Beyond Urban Legends" (Bioscience 200858 139-150) provide an initial framework for a theory of urban ecology. This article intends to contribute to the project by: 1) improving the philosophical rigor of critical concepts and epistemologies; 2) making explicit the complementary theoretical and empirical work in urban ecology already being done that can be better integrated, for example, studies from outside the U.S. and uses of actor network theory; 3 ) bringing forward more disciplines and theories which successfully deploy modes of thinking, research procedures, and practices more adequate to the phenomena at all scales and levels of particularity, i.e., micro, phenomenal, macro, to fill in some of the empirical gaps in the middle, specifically those having to do with human values and the richness of the everyday lifeworld. In addition to what is available within complexity theory itself, chief among the approaches to be utilized are phenomenology, ethnographic thick description, and actor network theory.
\end{abstract}

Key Words: biophysical-social systems; concepts; epistemology; theory; urban ecosystems

\section{INTRODUCTION}

Developing an adequate theory for urban ecology is occurring by transition through three stages. From the first era, in which the apparent dichotomy of humans and nature was reflected in the separation of the social and natural sciences (Marzluff et al. 2008:67-158), the move to the second phase now is underway as recent interdisciplinary work adopts frameworks linking social and ecological systems (Berkes and Folke 1998, Holling and Gunderson 2002, Berkes et al. 2003, Marzluff et al. 2008, Pickett et al. 2008). However, though such nowascendant approaches embrace complexity theory, seeing urban ecology in terms of open, hierarchical, dynamic interactions with emergent effects, most have not managed to pass out of the ontological, epistemological, or practical limitations of the old paradigm to fully accomplish the transformation. The literature of the current second phase is strongly marked by this tension between the explicit statements of holistic principles and the stilldominant use of dualistic concepts and operational procedures, a gap underscored by the small but growing number who actively attend to and commend theories that do complete the change and by the few scholars who succeed themselves.

My essay appreciates the importance of continuing the work done in the first two phases dealing with greater heterogeneity, scalar differences, and finer grain in abiotic, biotic, and human research and adding political reflection to planning and resource management. However, my main intention is to continue to develop the necessary new theory of knowledge and practices. Insofar as ecological systems result from continuous dynamic processes involving positive feedback loops then adequate scientific description and explanation require nondualistic concepts to serve as the codes we use to operationalize research that develops new knowledge. Similarly, critical practices are required for better decision making and adaptive comanagement.

Note that although my focused response is to Pickett et al. (2008), because their article develops the results of the Baltimore Ecosystem Study conducted as part of the Long Term Ecological Research Network, an opportunity presents itself to compare 
the parallel work by teams in Phoenix and Seattle (Grimm et al. 2000, Pickett et al. 2001, Pickett and Cadenasso 2002, Alberti et al. 2003, Alberti 2008) and beyond to notable work done in England (Hinchliffe and Whatmore 2006), Finland (YliPelkonen and Niemelä 2005), Germany (Wessolek 2008), and Sweden (Bodin et al. 2006, Colding et al. 2006, Ernstson et al. 2008), the last of which also engages Pickett et al. (2008). Hence, I proceed by incorporating my own contribution into a consideration of the international work already underway to articulate a fuller urban ecological theory. Finally, though I respect differences between urban and nonurban ecology (Berkes et al. 2003, Alberti 2005, Folke et al. 2005, Ernstson 2008a, Pickett et al. 2008), much of what is proposed here applies broadly to social-ecology and engages the concerns of nonurban scholars.

\section{GREATER PHILOSOPHICAL RIGOR}

Greater philosophical rigor is required in using empirical studies of structural and functional ecological relationships, specific methodologies, and the emerging integration of coupled biophysical and social features to achieve an adequate theory of urban ecology (Pickett et al. 2008). Two refinements can be made following from the opening their article provides: developing critical concepts and examining the assumptions that implicitly contain aspects of older epistemologies at odds with the requisite, newly emergent epistemology.

As a strategy, we need to speak plainly while remaining rigorous and consistent. Thus, Picket et al. (2008:139) reasonably begin their article by noting that "urban ecology is emerging as integrated science (Grimm et al. 2000)" that "aims to understand extensive urban areas that include not only biological and physical features but also built and social components (Cadenasso et al. 2006)." A principle task, then, is to talk sensibly about cities and lawns, earthworms and streams, yet also operate with precision by means of the concepts required for good science and theory.

Precision in regard to theory however is elusive, in part because of the term's variable meanings. Two major connotations are 1) big theory that articulates conceptual foundations and basic methodology and 2) subtheories that develop particularized conceptions and models. There is emerging consensus that the newly operative big theory is complex systems theory, which began with dissipative studies in physics and chemistry, then developed in biology, developmental and evolutionary studies, and cognitive science. There are many kinds of subtheories: the frameworks of formal modeling, ecological landscape models, i.e., spatial stochastic, process-based, and patch dynamics, and alternative classifications, i.e., gradient analysis, network theory, hierarchy theory. There are subtheories of ecological community, niche and dispersal, and others branching out into related disciplines, such as economics' agglomeration theories (Hubble 2001, Alberti 2008). A third sort of theory contests whether an integrated urban ecology would be a distinctive urban ecology theory (Trepl 1995), an extended general ecological theory (Niemalä 1999), or a hybrid theory (Alberti 2008). The contribution I hope to make here toward a theory of urban ecology lies not in unifying the dimensions of the big theory, but in suggesting ways we can include more subtheories, integrating them with each other and with the big theory. I do this in the following sections by first clarifying the relevant concepts, secondly sorting out the epistemological tangle in which confusing old dimensions unnecessarily hide the appropriate new theories already employed in ecology, then finally describing 12 proven qualitative approaches that can be merged with quantitative methods to more fully operationalize complexity theory thus cogenerating more comprehensive knowledge of ecological systems.

\section{CRITICAL CONCEPTS}

It not only is difficult to arrive at concepts adequate for a nonreductive, nonfragmented theory, but to use them consistently and without causing further confusions (Colyvan et. al 2009). The pathways of past thinking are hard to change because doing so requires imagining otherwise than according to the orientation already internalized. It is no harsh objection, then, to point out that we continually need to improve what we think and say. How else to proceed? Though agreeing with Pickett et al. that an integration of the concepts and phenomena of "human" and "natural" is needed, this essay argues that the most promising findings and implications remain held back by those elements that do not pass over to the new sciences of complexity. As a result, their article arrives at but does not fully accomplish the necessary theory of urban ecology, toward 
which end their stimulating essay would need to be revised at several points.

Although the authors properly oppose outdated modes of analysis by both ecologists and social scientists that "considered humans external 'disturbers' of natural systems," they nonetheless continue to develop their findings in terms that separate "urban social systems and urban environments" (McDonnell and Pickett 1993, as cited in Pickett et al. 2008:146-147). They write about "integrated social-ecological systems" (p.140), "findings of relationships between biophysical and social patterns and processes" (p.145), "lags [that] result from social and ecological change occurring at different rates" and "biogeochemical and social value" (pp.145-146). The result could be, at best, a theory that recognizes the dynamic inter-relationships between the two spheres, but that ultimately will fail by continuing to employ the untenable dualism. Surely we would agree by now that humans are within the physicalbiological domains, that organisms at many scales form communities, and that local ecologies have been generated by the codetermination and coevolution of human and nonhuman organisms. Thus, the exclusionary categories "ecological" and "social" perpetuate fundamental conceptual barriers to an integrative theory; they need not only to be corrected, but replaced as we develop another way of thinking that affirms that the ecological includes the human and other-than human, that is, all biota in their interconnected communities within geo-physical-chemical and climatic contexts (Latour 2004, Mugerauer 2010).

In fact, the authors have what is needed when they say, at the end of their essay, that their and others' results lead to a theory that "suggests that urban ecosystems are complex, dynamic, biologicalphysical-social entities, in which spatial heterogeneity and spatially localized feedbacks play a large role" (Cadenasso et al. 2006, as cited in Pickett et al. 2008:148). However, even when these properly critical terms are given, in the same breath the authors describe their successful step forward as connecting the "social processes and environmental structure and processes" (p.148). Other important contributions to the field remain in the same additive mindset: while affirming the inter-relational character of ecological phenomena, Berkes and Folke (1998) and Berkes et al. (2003) aim at "linking social and ecological systems," as do many who contribute along the same lines, though I cannot give evidential quotations from the more than two dozen such studies cited in this essay. The contradiction is obvious: what is not separated neither can, nor needs to be integrated, linked, or merely added together. Thus, much of what is said in this literature and what follows from it needs to be reset in more critically adequate terms.

Ecological scholarship has to explore the dynamic organism-environment relationships at and among every level of the continuous "arc of life" (R. Mugerauer, unpublished manuscript) that ranges from the energy flows of physical-chemical processes to cells, organs, whole organisms in Umwelts, other-than-human and human communities, ecosystems, and bio-cultural regions (Margulis and Sagan 1986, Morowitz 1992). With this "arc of life" as the integrating image, when we move from speaking about communities of other-than-human organisms to emphasizing human societies, we already operate within a comprehensive view of the world (Merleau-Ponty 1963, Mol 1999, Hinchliffe and Whatmore 2006, Mugerauer 2009a).

What all our colleagues in phase two say is clear enough: for example, when Pickett et al. say "social" they intend the "human" realm as distinct from "ecology", where the latter is understood as the sphere of nonhuman organisms and the biogeophysical milieu, or are focusing on the "human dominated" (2008:146). We don't need to be fanatical to the point of constantly correcting each other instead of listening. However, clearly, it is dangerous to continue to follow old habits of thinking that include not just unacceptable dualisms but also fundamentally flawed category mistakes that continue to mislead our research and interpretations. Indeed, many of the problematic concepts are inseparable from problematic epistemologies.

\section{NEW EPISTEMOLOGIES}

Explicitly comparing the older and newer epistemologies is another step toward a theory of integrated urban ecology. Because there is a continued dependence on and use of the older epistemologies at the same time as the newer ones differ significantly, indeed, are opposite in many respects, we need to determine where they might be compatible (agreeing perhaps on best available science, scenarios and modeling, the importance of heterogeneities and particularities) and where they 
are not. Basically, there are two dimensions of new epistemology that bear on the issues at hand: "complexity" and "postpositivist," or "postrepresentational”.

As to the first, the basis for much ecosystem and urban ecology investigation is found in the constellation of theories that include dissipative studies (Nicolis and Prigogine 1977), nonlinear mathematics (Ueda et al. 1993), self-organization (Kauffman 1993), autopoiesis (Maturana and Varela 1980), developmental systems theory (Oyama et al. 2001), dialectical biology (Levins and Lowentin 2007), and neurophenomenology (Varela et al. 1997). Because these dimensions of complex systems theory are not all the same, I speak of them as a constellation, though for simplicity's sake I often use the covering term "complexity theory." Much current ecological work operates within this sphere, deploying a network of concepts that include complexity, emergence, dynamic, and open systems far from equilibrium, nonlinearity, nonpredictability, bifurcations, positive feedback, heterogeneity, contingencies, and resilience, as we see with large portions of Pickett et al. (2008), Berkes et al. (2003), Heynen (2003), Borgstrom et al. (2006), though, as noted, problematically many of these accomplishments also partially continue to move in the older tradition.

The second set of emerging postpositivist, postpoststructuralist epistemologies includes the fundamentally continental cluster of phenomenology (Merleau-Ponty 1963, Heidegger 1977), enactivist theory (Varela et al. 1997), hermeneutics (Gadamer 1975), contextualism (Longino 2002), ethnography (de Certeau et al. 1998, Fischer 2003), and actor network theory (Stengers 1997, Latour 2004, 2005). These all challenge and would replace the up-tonow dominant epistemology and concepts of the modern scientific-technological epoch (Polkinghorne 1983, Pickering 1995).

Pickett et al. (2008) and others provide a focal point of discussion here because although they would pass over to an integrated theory, they continue to uncritically use concepts such as "representation," "prediction," and "cause." This practice seems doubly anomalous: it ignores the last thirty years' debate and contravenes the authors' own apparent intention because what can be said by way of these concepts neither fits within the new science nor allows their specific findings to fully unfold. "Representation," for example, is loaded with the problematic assumptions of an increasingly rejected metaphysics (Heidegger 1977), epistemology and methodologies (Rosenau 1992), and cognitivism (Varela et al. 1997). The new epistemologies stress that perception and cognition are not representations but performative constitutions (Pickering 1995, Zammito 2004, Latour 2004). This new direction need not lead to relativism, but instead to an appreciation of what we do in generating new meaning and of the importance of contextualized understanding (Longino 2002). Fruitful epistemological changes in urban ecology are beginning to appear: actor network theory is used to explicate how researchers, volunteers, water voles, and badgers unfold unexpected ecological relationships in Birmingham's postindustrial brownfields (Hinchliffe et al. 2005, Latour 2005, Hinchliffe and Whatmore 2006); analysis shows how new knowledge and values are generated in the course of the emerging comanagement of Stockholm's National Urban Park by officials together with user and interest groups (Barthel et al. 2005).

Even without the formal arguments against a representational view, we can see that Pickett and colleagues' practices using "representation" are a symptom showing that they continue to operate, in part, with traditional conceptualizations while also using incompatible new concepts and operators such as "resilience." For example, when helpfully describing how ordinary "land-use and land-cover classifications...are inadequate to capture coupled human-natural heterogeneity" Pickett et al. (2008:144) fail to capitalize on their own advance. While refining these classifications they do not acknowledge that this very reconceptualization is crucial in order to articulate phenomena in the first place. Instead, they fall into the inadequate formulation that "land-use maps do not represent ecological heterogeneity effectively" (Pickett et al. 2008:144). Rather than emphasizing the importance of their study for newly framing the issue, they speak only of "expos[ing] the finer scale heterogeneity in urban landscapes through increased categorical and spatial resolution," as if the same old idea of truth as unproblematic correspondence, simply refined in magnitude to appear more correct, was what they have to contribute: "preliminary results suggest that this more accurate representation of landscape heterogeneity better explains relationships with water quality than previously available land-use classifications (Cadenasso et al. 2007)" (Pickett et al. 2008:144). However, with the traditional concept of "representation" (and correlate visual "representation" of abstracted data) and its discredited foundational 
theory, their empirical achievement and advocacy for changing classifications falls far short of its potential, both in terms of a call to action and as theorized. So does that of many other teams. As Hinchliffe and Whatmore argue, more of the old kinds of information from increasingly detailed field surveys and case studies to fill in the gaps will never accomplish the transition to performative epistemology (2006). This unnecessarily holding back while moving forward haunts the work on biotopes (Colding 2007), scale (Heynen, 2003), vernacular ecology, and local knowledge (Barthel et al. 2005).

The deeper problem appears when Pickett et al. go on to the actually desired arena: the new sciences of complexity and the dynamic of urban ecology. They clearly intend to operate in the new field, as is seen in their central use of the term "coupling," which in autopoietic theory is opposite "representing." To represent requires that we would re-present in perception or cognition meanings that are assumed to be there prior to and independent of any interpreter, and that subsequently can be connected by us. Taken in this old way "coupling" would mean little more than adding components together, quite the contrary to what we attempt to think in the new epistemology with "emergence" in which a hierarchy of new systems and meanings is generated in an unpredictable way from the base components. The latter is what is explicated in core complexity theory (Stengers 1997) and as the dynamic of humans, nonhuman animals, and instruments in actor network theory (Callon 1986, Latour 2005); in the selection and cocreation of a niche by an organism (Oyama et al. 2001, OdlingSmee et al. 2003); or in enactive constitution by embodied consciousness (Varela et al. 1997). Hence, as a technical term introduced early on by Maturana and Varela, structural "coupling" connotes the recurring positive feedbacks that generate autocatalytic codevelopment in which the new emerges, rather than either representation or addition of what already exists (Maturana and Varela 1980:75).

Obviously when Picket et al. conclude that "couplings between social processes and environmental structure and processes have been demonstrated to shape the urban ecosystem" they intend the new science of enactive and codetermining processes and thus emerging phenomena (Pickett et al. 2008:148). Indeed, they go on to conclude the essay by saying just that: their theory "suggests that urban ecosystems are complex, dynamic biological-physical-social entities, in which spatial heterogeneity and spatially localized feedbacks play a large role (Cadenasso et al. 2006)" (Pickett et al. 2008:48). Further internal damage to their project's consistency and power resulting from this tension, if not contradiction, between the old, displaced epistemology and the new one of complexity broadly speaking, appears, for instance, when we consider their finding that challenges the initial assumption "that the ecological structure of particular neighborhoods reflects the existing social structure of those neighborhoods (Pickett et al. 2001)" (Pickett et al. 2008:145). Clearly the authors have interesting insights about the temporal differences in rate of change between trees and population demographics, yet make nothing of the open, coconstitutive dynamics among vegetation, nonhuman organisms, and human activity. This is quite a missed opportunity.

A parallel critique applies to the arguments of the new epistemologies that counter the still-dominant concept(s) of "causality" (Longino 2002, Zammito 2004). "Predict" and "explain," the central correlates to "causality," (Pickett et al. 2008:140) provide a case in point. Following from the sensitivity of phenomena to initial conditions and the contingency of most of what happens given random intersections within the universe, complexity theory insists that we can not predict future events as once was supposed by classical physics and operationalized with linear mathematics (Juarrero 1999, Alberti 2008). Of course, the nonlinear mathematics that generates attractors is the "replacement" in that it delineates patterns, allowing us to model phenomena and consider future scenarios (Longino 2002). However, continuing the historical trajectory from the natural sciences' abandonment of absolute certainty to its replacement by statistical probability and "best available explanations," both "explain" and "predict" bring us to the question of whether these concepts are to be taken in the sense still used within the current version of positive science or replaced with concepts that articulate the postpositivist (Polkinghorn 1983)? In the latter case, the task is to engage the fundamental questions as to how nonlinear and reciprocal causality and multiple possible coherent states can be understood and properly translated into science-technology and 
what "predict" would mean in urban ecology (Juarrero 1999, Schneider and Sagan 2005, Levins and Lewontin 2007).

Again, Pickett et al. (2008) operate right on the fracture line, intending to cross over to the new view, but remaining in the old, so that much of what they explicitly say is at odds with the implications of their findings. As a result, the promise is not fulfilled. As noted, they believe that their "preliminary results suggest that this more accurate representation of landscape heterogeneity better explains relationships with water quality than previously available landuse classifications (Cadenasso et al. 2007)" (Pickett et al. 2008:144). What would "explain" mean here if not something like account for in terms of traditional uni-directional causality? This reading is supported by the other passage that advocates "better understanding of urban ecosystems," but then relapses into the traditional formulation by adding "and for improvement of the theory to explain and predict their dynamics" (Pickett et al. 2008:140). There is no indication that "explain and predict" have other than the old meanings, no engagement with what prediction means in the new sciences.

Adequate theory needs to shift from the older conceptualizations of the universal and predictable to a postpositivist stress on probability and generalizations, where plural epistemologies are used to deal with empirical particularity. This can be done while avoiding the excesses of poststructuralism, in which some contended that recognizing that humans historically constitute meaning entails the relativistic conclusion that any meaning is as good as any other or that scientific writing is "merely fiction," oblivious to the fact that plural meaning still has "nonsense" and "falsity" as its contraries and that processes, materials, and organisms, however plastic, have limits, as is clear from "law" connoting "constraint" (Mugerauer 1991, Longino 2002, Latour 2005). Thus the exceptional power of the new epistemology: that there might be sciences of the singular and contextualized knowledge that do not give up legitimate scientific generalizations and that can be modeled and tested, conceding only the unhelpful fantasy of certainty which, in principle and fact, is impossible for science to realize (Fischer 2003, Levins and Lewontin 2007, Colyvan et al. 2009).

\section{EMPIRICAL DESCRIPTION AND ANALYSIS AT THE PHENOMENAL SCALE OF THE LIFEWORLD}

In order to explicitly contribute to integrating subtheories with each other and with the big theory this section 1) specifies 12 approaches demonstrably correlate with the natural and social science work being done and 2) for the most telling examples either cites fusions already underway or suggests how they might easily operate together to better deploy complexity theory in ecological research and management. Obviously ecological study ranges from the microrealm of biochemical reactions, through the phenomenal domain of ordinary human perception, to the macrorealms of the atmosphere, lithosphere, and hydrosphere. However, as the psychiatrist Erwin Straus points out, to be empirical, "we should turn our attention back to the observable phenomena. The wellspring is everyday life experience." To be clear: the phenomenal realm is that which is directly given to us in our ordinary routines. This "frame of reference from which we start and to which we return is the structure of the everyday lifeworld - the reality familiar and common to all" made up of plants, animals, people, things, and events is an integrated, communally-constituted sphere of meaningful activity (1966:257). It is where we encounter, as Holling puts it, "the bewildering, entrancing, unpredictable nature of nature and people, the richness, diversity, and changeability of life" (2003: $\mathrm{Xv})$. The relation of the lifeworld to the sciences is that of the primary to the secondary: it is from the lifeworld that we abstract and formalize the concepts and subject matter of scientific knowledge and beyond which we project ourselves with microscopes, telescopes, other imaginative

instrumentation, and inferences. Because the lifeworld is the sphere that we take for granted, its implicit structures need to be made explicit by reflection; though it emerges from atomic events and cosmic forces which thus are part of its explanation, the lifeworld must not be reduced to its constitutive dimensions, as complexity theory well demonstrates.

In fact, the phenomenological term "lifeworld" originated as a way to avoid dualisms such as nature and culture and to prevent abstracting so far from the particulars that we cannot reintegrate our mathematical, graphic, or other symbolic understanding with the common human experience 
(Straus 1966:257). If we lose what motivates and grounds the science and practices of urban ecology, we also lose the basis for social life and politicalenvironmental decision making (Flyvbjerg 2001), for example, the fact that:

\begin{abstract}
In the global city of our civilization, girded by ... our powerlines, we have abolished the night. ... We stand in danger of losing something crucial ... We tend to lose sight, literally as well as metaphorically, of the rhythm of the day and the night, of the phases of the moon and the change of the seasons, of the life of the cosmos and of our place therein. (Kohák 1984:x)
\end{abstract}

The reflective task is to bring forth the character of our experiential realms, including our way of life or ethos, in a manner that does not lose the qualitative aspects. This is accomplished by providing thick narrative or graphic description (Geertz 1973), then identifying and analyzing the structures of experience that organize the phenomena's occurring as it does, the results of which open to further investigation by empirical and imaginative variation, and finally, as in all science, to debating whether a given provisional understanding is the best available interpretation (Gallagher and Zahavi 2008).

Appropriate qualitative empirical descriptions and analysis of ecosystems and the structure of lifeworlds can both fill in the gap between the microand macrospheres and supplement quantitative analysis of abstractions such as ecosystem services or class. I propose that the following cluster of proven approaches that provide such holistic interpretation should be developed together with methods already employed, as is beginning to happen with actor network theory. Urban ecologists have long advocated the use of historical research (Sörlin 1998, Berkes et al. 2003:6-7, Barthel et al. 2005), qualitative empirical analysis of written documents and open-ended interviews (Borgström et al. 2006), participant observation (Callon 1986, Ernstson and Sörlin 2009), qualitative ecosystem indicators (Stefanovic 2000), and attention to sense of place (Andersson et al. 2007) and to the values of diverse groups (Yli-Pelkonen and Niemelä 2005).

In regard to methods, one of the most valuable contributions of the Pickett et al. (2008) essay is the use of empirical studies to provide substance to urban ecological research and to generate a framework for comprehensive investigation. A spectrum of phenomena and methods is covered by the results from the Baltimore Ecosystem Study in a way that allows developing integrated scientific practices and theory. As throughout, proceeding from their essay is not to argue against what they present, but to complement it. Rather than abstractly inventing an a priori theoretical construct, then applying it to "account" for scientific activity and findings, the actual cycles of investigation and interpretation present the phenomena in a way that their meanings, assumptions, and implications suggest fruitful directions toward articulating a legitimizing integrated theory (Pickering 1995).

Though their essay covers a diverse set of specific studies the emphasis is on two domains within scientific inquiry: the chemical and social perception-class relationships. Clearly, the attempt to make progress in knowledge about complex physical-bio-cultural phenomena does not require an impossible simultaneous comprehension of the whole. Both dualisms and reductivisms can be avoided while investigating features discerned as distinct though not actually separated. The play between figure and ground is unavoidable and unproblematic given the hermeneutic circle of understanding in which we move back and forth from part to emerging whole, from empirical detail to legitimate generalization (Gadamer 1975). Already within such a process, the empirical investigations of Pickett et al., teams from the other sites in the Long Term Ecological Research Network, and European contributors to the Millennium Ecosystem Assessment provide documentation and analysis at a finer scale, the case studies of Stockholm add allotment gardens, parks, and golf courses as biotopes and gardeners, urban planners, and cemetery administrators as managersusers (Barthel et al. 2005, Alberti 2008, Ernstson and Sörlin 2009). However, as discussed above, though refined detail about local sites is important and welcome, insofar as the results are from surveys that provide data that is still only additive and representationally understood the information falls short of what could be achieved. In contrast, an advance occurs when findings are interpreted enactively (Varela et al. 1997): exemplary studies explicitly trace how an expanded actor network generates more effective democratic decision making and resource management (Hinchliffe et al. 2005, 2006, Ernstson 2008a, Ernstson and Sörlin 2009), or emphasize actors and active management 
to supplement the more dominant focus on land use (Ernstson et al. 2010).

In applying complexity theory Pickett et al. (2008) present useful findings in regard to stream nitrate loading, carbon sequestration, and the biogeochemistry of lawns. Particularity is especially important for the group's emphasis on patch dynamics, spatialprocess heterogeneity, and gradients between assumptions and actual findings (2008:140,148). The research successfully moves from the chemical toward the realm of life itself, opening to soil, vegetation, avifauna, and human health, at which point it should be supplemented by the detailed empirical contributions available through developmental systems theory (Oyama et al. 2001), constructionist development (Levins and Lewontin 2007), and enactivism (Varela et al. 1997), though I cannot detail that here. As a positive example of treating the midscale phenomenal realm as well as the microand macrospheres in their complexity, Wessolek (2008) combines traditional verbal and visual data, detailed description of the interactions among biotic and abiotic elements, and easily-readable, story-like illustrations.

With an eye to practical land use management, Pickett et al. consider findings regarding relationships between "social status and awareness of environmental problems, and between race and environmental hazard" and "social-biophysical feedbacks" (2008:139,144). In addition to further data, a full phenomenology is required because the disparate biogeophysical processes are coconstituted with human inhabitants, thus involving historical patterns of development, aesthetics, domestic values, ideals of citizenship, social status, and even the "myth" of controlling nature (Schroeder 1993, Jenkins 1994, Heynen et al. 2006, Robbins and Sharp 2008). Thus, in the lawn we find writ small the larger problem: urban ecology, for all its success within the second phase of linking the social and ecological, fails to achieve a consistent transformation to integrated complexity in the ontological, epistemological, and practical political spheres. Traditional data-oriented studies do not present the lifeworld phenomena; urban ecology studies dealing with inequalities of ecosystem services distribution may be innocent of landscape ideology (Ernstson, 2008b); urban political ecologies that detail the socially uneven benefits of tree cover across scales may leave us without an understanding of the actual ecosystem dynamics (Heynen 2003, Latour 2004, Walker 2005).
In any case, generalizations proper to data-oriented social science unavoidably conceal part of what is newly appreciated at the heart of complexity theory and postpositive epistemologies: the heterogeneity of phenomena, variously couched in terms of the local or patch dynamics and cross-scale sensitivity (Berkes et al. 2003, Fischer 2003, Pickett et al. 2008:140) and experienced in the lifeworld in terms of qualitative differences (Erikson 1976). Since data and concepts can tell only part of the story, the abstracting social and natural sciences can be complemented by narrative and visualization that, especially when informed by literature and the arts, can evoke otherwise absent rich detail. Vivid narratives can bring forth the phenomenality of our experience, with its multiplicity, ambiguity, and nuance, so that the lifeworld can emerge both in the "singularity of its own local context" and in regard to what it "contributes to our generalized understanding" as the phenomenological sociologist Kai Erikson puts it (1976:246-247).

Weaving the two dimensions together, Erikson writes about a disaster in West Virginia, describing how a crude composite impoundment of silt and sludge, mining slag, metal and timber refuse collapsed, so the 132 million gallons of water "black with coal dust and thick with solids" that it precariously held back broke through, crashing to the valley below as a "writhing mass" that "scraped up thousands of tons of other materials [rocks, trees, houses, trucks], the whole being fused into a liquid substance that one engineer simply called a 'mud wave', ... a churning maelstrom of liquid and mud and debris, curling around its own center and grinding its way relentlessly into Buffalo Creek," a minute or two later landing on the town of Saunders, carrying it away entirely (Erikson 1976:25-31)

Because the task is not just to depict data in figures that are "correct" illustrations, graphics can be used to let the qualities of the lifeworld emerge: this may happen through diagramming the dynamic relationships of actors "producing narratives that are able to explain...why just a certain set of values are allowed to resonate through protective stories" (Ernstson and Sörlin 2009:107) or by incorporating drawings into the ethnoecology of New Jersey's Pinelands where:

The landscapes of corduroy roads, charcoal pits, curly grass ferns, and pine barrens tree frogs are intimately intertwined. Woodsmen who removed sphagnum and turf from the 
swampy areas unintentionally produced the habitats favorable to today's rare and celebratedflora and fauna. Because the turf was used for insulating charcoal pits and for building cranberry bogs, turfing is no longer a common practice. (Hufford 1986:70)

Such stories identify and describe ways of life, realms where both human and other-than-human organisms in interactive relationships with their environments generate spheres of meaning, fields of action, as the ethologist von Uexküll (1909) brilliantly explained, using the term Umwelt, i.e., "surround world," which for all practical purposes also can be translated as "lifeworld." In the strictest sense there is an Umwelt only when an organismenvironment coupling occurs, which means that ecosystems consist of their many organisms' qualitatively distinct realms of experience, sometimes overlapping, often not. Just as these qualitatively distinct lifeworlds can not be fully understood without comprehending the physicalchemical-biological dimensions or communal relationships of human and nonhuman organisms, neither can they be comprehended without an adequate identification, description, and analysis of the constitutive structures of experience. The point is not which of the many empirical approaches are used but that the particularity of the lifeworld experience has to be brought forth for urban ecology as the middle-scale complement to the micro- and macrospheres. We need the lifeworld in the flesh, as it were, to engage the phenomena of greatest concern, "large urban areas as bio-physical-social complexes," that is, "urban ecological systems" (Pickett et al. 2008:139), in a mode that helps us recognize, acknowledge, and understand problems that need to be dealt with: poisoned ground water, flooding, or unequal access to resources.

\section{CONCLUSION}

In the ascendant second and emerging third phase of ecological theory, the new sciences of complexity are providing for the integrated understanding of dynamic processes, while a variety of congruent approaches inform policy decisions and practices. Epistemologically, as the population statistician and scientist Levins argues, though ecology does not seek universal rules because of the differences among places it nonetheless can discern patterns in the dynamic processes generating those differences so that specificity and generalizations are found together (2007:97-98). Politically, we can understand "concrete particularizing situations," in a manner that enables "a practical science of the singular" (de Certeau et al. 1998:256). This can be enacted through the empirical phenomenology of the lifeworld that describes and analyzes diverse perceptions and responses to local ecologies. It can happen through actor network theory that studies what human and nonhuman actors do in producing and managing urban ecosystems (Latour 2004, Hinchliffe et al. 2005, 2006, Ernstson 2008a). It can occur as responsible environmental action increasingly shifts from preservation and conservation to restoration, and most recently to resilience (Walker and Salt 2006); or, as increasingly comprehensive mathematical models, visualizations, and narrative scenarios allow us to publicly debate the plausibility of alternative courses of action (Alberti 2008, Mugerauer 2009b). Such promising openings toward more effective knowledge and action should motivate us to continue collaborations toward a theory of integrated urban ecology.

Responses to this article can be read online at: http://www.ecologyandsociety.org/voll5/iss4/art31/ responses/

\section{Acknowledgments:}

I am grateful to Pickett and colleagues (in their various combinations) for their earlier works and specifically for the way "Beyond Urban Legends" opens to others contributing to developing a theory of integrated urban ecology. As something of an outsider who shares an interest in the same subject matter even if with a different approach and vocabulary, I want to make clear that this essay is intended to compliment their and others' good work as well as to complement it in the sense of making a positive addition toward the new framework. I also want to thank the reviewers and editors of Ecology and Society for their exceptionally constructive criticism, conveyed in a spirit of inclusion and collaboration. 


\section{LITERATURE CITED}

Alberti, M. J. 2005. The effects of urban patterns on ecosystem function. International Regional Science Review. 28(2):168-192.

Alberti, M. J. 2008. Advances in urban ecology: integrating humans and ecological processes in urban ecosystems. Springer, New York, New York, USA.

Alberti, M. J., J. Marzluff, E. Shulenberger, G. Bradley, C. Ryan, and C. Zumbrunnen. 2003. Integrating humans into ecology: opportunities and challenges for studying urban ecosystems. BioScience 53(12):1169-1179.

Andersson, E., S. Barthel, and K. Ahrné. 2007. Measuring social-ecological dynamics behind the generation of ecosystem services. Ecological Applications 17(5):1267-1278.

Barthel, S., J. Colding, T. Elmqvist, and C. Folke. 2005. History and local management of a biodiversity-rich, urban cultural landscape. Ecology and Society 10(2): 10. [online] URL: http://www.e cologyandsociety.org/vol10/iss2/art10/.

Berkes, F., and C. Folke, editors. 1998. Linking social and ecological systems: management practices and social mechanisms for building resilience. Cambridge University Press, Cambridge, UK.

Berkes, F., J. Colding, and C. Folke, editors. 2003. Navigating social-ecological systems: building resilience for complexity and change. Cambridge University Press, Cambridge, UK.

Bodin, Ö., B. Crona, and H. Ernstson. 2006. Social networks in natural resource management: what is there to learn from a structural perspective? Ecology and Society 11(2): r2. [online] URL: http:/ /www.ecologyandsociety.org/vol11/iss2/resp2/.

Borgström, S., T. Elmqvist, P. Angelstam, and C. Alfsen-Norodom. 2006. Scale mismatches in management of urban landscapes. Ecology and Society 11(2): 16. [online] URL: http://www.ecolog yandsociety.org/vol11/iss2/art16/.

Callon, M. 1986. Some elements of a sociology of translation: domestication of the scallops and the fishermen of St. Brieuc Bay. Pages 196-233 in J.
Law, editor. Power, action and belief. Routledge \& Kegan Paul, London, UK.

Cadenasso, M. L., S. T. A. Pickett, and J. M. Grove. 2006. Dimensions of ecosystem complexity: heterogeneity, connectivity, and history. Ecological Complexity 3:1-12.

Cadenasso, M. L., S. T. A. Pickett, and K. Schwarz. 2007. Spatial heterogeneity in urban ecosystems: reconceptualizing land cover and a framework for classification. Frontiers in Ecology and Evolution 5:80-88.

Colding, J. 2007. 'Ecological land-use complementation' for building resilience in urban ecosystems. Landscape and Urban Planning 81:46-55.

Colding, J., J. Lundberg, and C. Folke. 2006. Incorporating green-area user groups in urban ecosystem management. Ambio 35(5):237-244.

Colyvan, M., S. Lindquist, W. Grey, P. Griffiths, J. Odenbaugh, and H. P. Possimgham. 2009. Philosophical issues in ecology: recent trends and future directions. Ecology and Society 14(2): 22. [online] URL: http://www.ecologyandsociety.org/voll4/ iss $2 / \operatorname{art} 22 /$.

de Certeau, M., L. Giard, and P. Mayol. 1998. The practice of everyday life. Volume 2: living and cooking. University of Minnesota Press, Minneapolis, Minnesota, USA.

Erikson, K. T. 1976. Everything in its path: destruction of community in the Buffalo Creek Flood. Simon and Schuster, New York, New York, USA.

Ernstson, H. 2008a. In Rhizomia: actors, networks and resilience in urban landscapes. Dissertation. Stockholm University, Stockholm, Sweden.

Ernstson, H. 2008b. The social production of ecosystem services: lessons from urban resilience research. In H. Ernstson. In Rhizomia: actors, networks and resilience in urban landscapes. Dissertation. Stockholm University, Stockholm, Sweden.

Ernstson, H., S. Barthel, E. Andersson, and S. T. Borgström. 2010. Scale-crossing brokers and network governance of urban ecosystem services: the case of Stockholm, Sweden. Ecology and 
Society 15(4): 28. [online] URL: http://www.ecolog yandsociety.org/vol15/iss4/art28/.

Ernstson, H., and S. Sörlin. 2009. Weaving protective stories: connective practices to articulate holistic values in the Stockholm National Urban Park. Environment and Planning A 41:1460-1479.

Ernstson, H., S. Sörlin, and T. Elmqvist. 2008. Social movements and ecosystem services-the role of social network structure in protecting and managing urban green areas in Stockholm. Ecology and Society 13(2): 39. [online] URL: http://www.e cologyandsociety.org/vol13/iss2/art39/.

Fischer, M. J. 2003. Emergent forms of life and the anthropological voice. Duke University Press, Durham, North Carolina, USA.

Flyvbjerg, B. 2001. Making social science matter. Cambridge University Press, Cambridge, UK.

Folke, C., T. Hahn, P. Olsson, and J. Norberg. 2005. Adaptive governance of social-ecological systems. Annual Review of Environmental Resources 30:441-473.

Gadamer, H.-G. 1975. Truth and Method. Seabury Press, New York, New York, USA.

Gallagher, S., and D. Zahavi. 2008. The phenomenological mind: an introduction to philosophy of mind and cognitive science. Routledge, New York, New York, USA.

Geertz, C. 1973. The interpretation of cultures. Basic Books, New York, New York, USA.

Grimm, N. B., J. M. Grove, S. T. A. Pickett, and C. L. Redman. 2000. Integrated approaches to long-term studies of urban ecological systems. BioScience 50:571-584.

Heidegger, M. 1977. The question concerning technology. Harper and Row, New York, New York, USA.

Heynen, N. C. 2003. The scalar production of injustice within the urban forest. Antipode35:980-998.

Heynen, N. C., M. Kaika, and E. Swyngedouw, editors. 2006. In the nature of cities: urban political ecology and the politics of urban metabolism. Routledge, Oxford, UK.
Hinchliffe, S., M. Kearnes, M. Degen, and S. Whatmore. 2005. Urban wild things: a cosmopolitical experiment. Environment and Planning D: Society and Space 23:643-658.

Hinchliffe, S., and S. Whatmore. 2006. Living cities: towards a politics of conviviality. Science as Culture 15(2):123-138.

Holling, C. S. 2003. Forward. Pages xv-xx in F. Berkes, J. Colding, and C. Folke, editors. Navigating social-ecological systems: building resilience for complexity and change. Cambridge University Press, Cambridge, UK.

Holling, C. S., and L. H. Gunderson. 2002. Panarchy: understanding transformations in human and natural systems. Island Press, Washington, D.C., USA.

Hubble, S. P. 2001. The unified neutral theory of biodiversity and biogeography. Princeton University Press, Princeton, New Jersey, USA.

Hufford, M. 1986. One space, many places: folklife and land use in New Jersey's Pinelands National Reserve. American Folklife Center, Library of Congress, Washington, D.C., USA.

Jenkins, V. S. 1994. The lawn: a history of an American obsession. Smithsonian Institution Press, Washington, D.C. USA.

Juarrero, A. 1999. Dynamics in action: intentional behavior as a complex system. MIT Press, Cambridge, Massachusetts, USA.

Kauffman, S. A. 1993. The origins of order: selforganization and selection in evolution. Oxford University Press, New York, New York, USA.

Kohák, E. 1984. The embers and the stars. Chicago University Press, Chicago, Illinois, USA.

Latour, B. 2004. Politics of nature: how to bring the sciences into democracy. Harvard University Press, Cambridge, Massachusetts, USA.

Latour, B. 2005. Reassembling the social: an introduction to actor-network-theory. Oxford University Press, New York, New York, USA. 
Levins, R. 2007. Ten propositions on science and antiscience. Pages 87-99 in R. Levins and R. Lewontin. Biology under the influence. Monthly Review Press, New York, New York, USA.

Levins, R., and R. Lewontin. 2007. Biology under the influence. Monthly Review Press, New York, New York, USA.

Longino, H. 2002. The fate of knowledge, science as social knowledge: values and objectivity in scientific inquiry. Princeton University Press, Princeton, New Jersey, USA.

Margulis, L., and D. Sagan. 1986. Microcosmos: four billion years of evolution from our microbial ancestors. University of California Press, Berkeley, California, USA.

Marsluff, J. M., E. Shulenberger, W. Endlicher, M. Alberti, G. Bradley, C. Ryan, C. ZumBrunnen, and U. Simon, editors. 2008. Urban ecology: an international perspective on the interaction between humans and nature. Springer, New York, New York, USA.

Maturana, H. R., and F. J. Varela. 1980. Autopoiesis and cognition: the realization of the living. Reidel Publishing, Boston, Massachusetts, USA.

Merleau-Ponty, M. 1963. Structure of human behavior. Duquesne University Press, Pittsburg, Pennsylvania, USA.

Mol,A. 1999. Ontological politics: a word and some questions. Pages 74-89 in J. Law and J. Hassard, editors. Actor network theory and after. Blackwell, Oxford, UK.

Morowitz, H. J. 1992. Beginnings of cellular life: metabolism recapitulates biogenesis. Yale University Press, New Haven, Connecticut, USA.

Mugerauer, R. 1991. Post-structuralist planning theory. The University of Texas Community and Regional Planning Program Working Paper Series, Austin, Texas, USA.

Mugerauer, R. 2009a. The double-gift: place and identity. Pages 68-92 in I. Aravat, editor. Experience, memory, thought. Technion University Press, Haifa, Israel.
Mugerauer, R. 2009b. Scenarios for ecological design. Environmental and Architectural Phenomenology 20(2):8-9.

Mugerauer, R. 2010. The city: a legacy of organism-environment interaction at every scale. In I. L. Stefanovic and S. Scharper, editors. The natural city: revisioning the built environment. University of Toronto Press, Toronto, Ontario, Canada, in press.

Nicolis, G., and I. Prigogine. 1977. Selforganization in non-equilibrium systems. John Wiley \& Sons, New York, New York, USA.

Niemelä, J. 1999. Is there a need for a theory of urban ecology? Urban Ecosystems 3:57-65.

Odling-Smee, F. J., K. N. Laland, and M. W. Feldman. 2003. Niche construction: the neglected process in evolution. Princeton University Press, Princeton, New Jersey, USA.

Oyama, S., P. E. Griffiths, and R. D. Gray, editors. 2001. Cycles of contingency: developmental systems and evolution. MIT Press, Cambridge, Massachusetts, USA.

Pickering, A. 1995. The mangle of practice: time, agency, and science. University of Chicago Press, Chicago, Illinois, USA.

Pickett, S. T. A., and M. L. Cadenasso. 2002. The ecosystem as a multidimensional concept: meaning, model, and metaphor. Ecosystems 5:1-10

Pickett, S. T. A., M. L. Cadenasso, J. M. Grove, P. M. Groffman, L. E. Band, C. G. Boone, W. R. Burch, S. B. Grimmond, J. Hom, J. C. Jenkins, N. L. Law, C. H. Nilon, R. V. Pouyat, K. Szlavecz, P.S. Warren, and M. Wilson. 2008. Beyond urban legends: an emerging framework of urban ecology, as illustrated by the Baltimore ecosystem study. Bioscience 58:139-150.

Pickett, S. T. A., M. L. Cadenasso, J. M. Grove, C. H. Nikon, E. V. Pouyat, W. C. Zipperer, and B. Constanza. 2001. Urban ecological systems. Linking terrestrial ecological, physical, and socioeconomic components of metropolitan areas. Annual Review of Ecology and Systematics 32:127-157. 
Polkinghorne, D. 1983. Methodology for the human sciences: systems of inquiry. SUNY Press, Albany, New York, USA.

Robbins, P. and J. T. Sharp. 2008. Producing and consuming chemicals: the moral economy of the American lawn. Pages 181-205 in J. M. Marsluff, E. Shulenberger, W. Endlicher, M. Alberti, G. Bradley, C. Ryan, C. ZumBrunnen, and U. Simon, editors. Urban ecology: an international perspective on the interaction between humans and nature. Springer, New York, New York, USA.

Rosenau, P. M. 1992. Post-modernism and the social sciences. Princeton University Press, Princeton, New Jersey, USA.

Schneider, E. D., and D. Sagan. 2005. Into the cool: energy flow, thermodynamics, and life. University of Chicago Press, Chicago, Illinois, USA.

Schroeder, F. 1993. Front yard America: the evolution and meanings of a vernacular domestic landscape. Bowling Green State University Popular Press, Bowling Green, Ohio, USA.

Sörlin, S. 1998. Monument and memory: landscape imagery and the articulation of territory. Worldviews: Environment, Culture, Religion. 2:269-279.

Stefanovic, I. L. 2000. Phenomenological reflections on ecosystem health. Ethics and Environment 5(2):253-269.

Stengers, I. 1997. Power and invention: situating science. University of Minnesota Press, Minneapolis, Minnesota, USA.

Straus, E. 1966. Phenomenological psychology. Basic Books, New York, New York, USA.

Trepl, L. 1995. Towards a theory of urban biocoenoses. Pages 3-21 in H. Sukopp, M. Numata, and A. Huber, editors. Urban ecology as the basis for urban planning. SPB Academic, The Hague, The Netherlands.

Ueda, Y., J. S. Thomsen, J. Rasmussen, and E. Mosekilde. 1993. Behavior of the solution to Duffing's equation for large forcing amplitudes. Mathematical Research 72:149-166.
Varela, F., E. Thompson, and E. Rosch. 1997. The embodied mind: cognitive science and human experience. MIT Press, Cambridge, Massachusetts, USA.

von Uexküll, J., 1909. Umwelt und Innerwelt der Tiere. Springer, Berlin, Germany.

Walker, B., and D. Salt. 2006. Resilience thinking: sustaining ecosystems and people in a changing world. Island Press, Washington D.C., USA.

Walker, P. A. 2005. Political ecology: where is the ecology? Progress in Human Geography 29 (1):73-82.

Wessolek, G. 2008. Sealing of soils. Pages 161-179 in J. M. Marsluff, E. Shulenberger, W. Endlicher, M. Alberti, G. Bradley, C. Ryan, C. ZumBrunnen, and U. Simon, editors. Urban ecology: an international perspective on the interaction between humans and nature. Springer, New York, New York, USA.

Yli-Pelkonen, V., and J. Niemelä. 2005. Linking ecological and social systems in cities: urban planning in Finland as a case. Biodiversity and Conservation 14:1947-1967.

Zammito, J. 2004. A nice derangement of epistemes: post-positivism in the study of science from Quine to Latour. University of Chicago Press, Chicago, Illinois, USA. 